Ariel Diamant · Hein von Westernhagen

\title{
MARS: biological indicators of natural and man-made changes in marine and coastal waters: scientific coordinators' introduction
}

Received: 10 March 2003 / Revised: 11 June 2003 / Accepted: 3 July 2003 / Published online: 22 August 2003 (C) Springer-Verlag and AWI 2003

\section{Foreword}

The present issue presents the outcome of the GermanIsraeli cooperative project in Marine Sciences (MARS) 'Biological Effects Monitoring' as an integral part of the agreement on scientific research and technological development between the German Federal Ministry of Education and Research (BMBF) and the Israel Ministry of Science, Culture and Sport (MOS). Both phases, MARS 1 (1995-1998) and MARS 2 (1998-2001) were sponsored and coordinated by the BMBF through its project management group (Projektträger BEO) and the GKSS Research Center, Geesthacht GmbH. MARS dealt with the application of potential biological effects monitoring methods (MARS $1 / 1-3$ and MARS $2 / 1-2$ and MARS Statistical Data Analysis). Overall, it included the following subprojects: MARS $1 / 1$ - the use of marine fish and bivalves for biomarker based pollution monitoring in coastal areas; MARS 1/2 - the use of fish metabolic, pathological and parasitological indices in pollution monitoring; MARS 1/3 - hydrogen peroxide in coastal waters: an early tracer of pollution and its biological impact; MARS 2/1 - the use of marine fish and bivalves for biomonitoring of natural and man-made pollution in coastal areas; MARS 2/2 - the use of fish parasitological, metabolic and immunological indices in pollution monitoring; MARS 2/3-biological cycling of inorganic carbon: its ecophysiological significance and its implications or geochemical and biological probes of $\mathrm{CO}_{2}$ concentration in the marine environment; MARS 2 Statistical Data Analysis-assimilation, statistical analysis

Communicated by H. von Westernhagen, A. Diamant

\section{A. Diamant}

National Center of Mariculture,

Israel Oceanographic and Limnological Research Ltd., P.O. Box 1212, 88112 Eilat, Israel

H. von Westernhagen $(\bullet)$

Alfred-Wegener-Institute for Polar and Marine Research, Columbusstrasse, 27568 Bremerhaven, Germany

e-mail: hwesternhagen@web.de and synthesis. The close collaboration between German and Israeli scientists is reflected by the many reciprocal work visits carried out during the 6-year-long project, summarized in Table 1. These cooperative activities also yielded 6 M.Sc. and 4 Ph.D. theses, as well as numerous scientific papers.

\section{Introduction}

The scientific literature includes a wealth of papers dealing with the art of tracking environmental changes by monitoring inhabitant organisms, based on the principle that life forms may provide information about the environment they live in. The science of environmental biomonitoring typically involves the use of a suite of selected bioindicators, which may be at different levels of biological organisation. These tools are employed to assess sub-lethal effects on biological systems at the cell, organ, individual or community level. The main features of biomarkers (so called when at organism, tissue or cell level) and bioindicators (when at population, community or ecosystem level) are described by McCarty and Munkittrick (1996) as "an anthropogenically induced variation in biochemical, physical, or ecological components or processes, or functions that has been either statistically correlated or causally linked, in at least a semiquantitative manner, to biological effects at one or more of the organisms, population, community, or ecosystem levels of biological organization". Researchers are constantly focusing on standardising protocols and their integration into suites of probes, biomarkers and bioindicators, with the emerging techniques of each decade reflecting the current state-of-the-art: at present sophisticated microscopy, analytical chemistry and molecular biology. Unfortunately, many bioindicators still possess a degree of ambiguity that limits their use with regard to subtle changes in the environment.

Levels of pollutants in the environment may be accurately measured with sophisticated, state-of-the-art instrumentation. However, chemicals often have no 
Table 1 Visits of MARS participants to Israel and Germany between 1995 and 2002. JAC Joint Advisory Committee

\begin{tabular}{|c|c|c|c|c|c|c|c|}
\hline 1995-2002 & $\begin{array}{l}\text { MARS 1/1 } \\
\text { and } 2 / 1\end{array}$ & $\begin{array}{l}\text { MARS 1/2 } \\
\text { and } 2 / 2\end{array}$ & MARS $1 / 3$ & MARS $2 / 3$ & $\begin{array}{l}\text { Statistics and } \\
\text { chemistry }\end{array}$ & $\begin{array}{l}\text { JAC and scientific } \\
\text { coordinators }\end{array}$ & Total \\
\hline $\begin{array}{l}\text { To Israel } \\
\text { To Germany }\end{array}$ & $\begin{array}{l}11 \\
18\end{array}$ & $\begin{array}{l}30 \\
10\end{array}$ & $\begin{array}{l}3 \\
4\end{array}$ & $\begin{array}{l}2 \\
5\end{array}$ & $\begin{array}{l}3 \\
4\end{array}$ & $\begin{array}{l}12 \\
12\end{array}$ & $\begin{array}{l}61 \\
53\end{array}$ \\
\hline Total & 29 & 40 & 7 & 7 & 7 & 24 & 114 \\
\hline
\end{tabular}

observable effect on organisms living in the environment and, while some do, their effect may only be ephemeral. Others, that remain stable for long periods, may have long-lasting effects. Moreover, the unpredictability of pollutant effect at different sites, even when situated adjacently, may be remarkable. The effect of a contaminant on a given organism is typically related to its incorporation into the living body, which in turn is dependent on a wide range of factors. Since we are primarily looking for biological effects and not simply evidence of increased pollution levels, when we bear in mind cause/effect relationships, the interpretation of chemical data may become extremely tricky. Thus new, innovative methods must be constantly developed and tested.

Although 'biological effects monitoring' was off to a late start when compared to 'chemical monitoring' or 'biological monitoring' - both of which have been in operation in the North Sea area since the initiation of the Joint Monitoring Programme in 1979-it has advanced significantly in recent years. In its last report, the ICES Working Group on Biological Effects of Contaminants (Anonymous 2002) provided an extensive list of "recommended techniques for biological monitoring programmes at the national or international level" that lists 19 different approaches (Table 2) in addition to a further 12 "promising biological effects monitoring methods which require further research before they can be recommended for monitoring". A key aspect of all these is to provide indication for both exposure and pathology. One of the reasons for the diversity of methods is that, even though the establishment and measurement of 'biomarker responses' may offer evidence of damage at the cellular or sub-cellular level, it may not provide assessment of environmental damage at higher levels of biological organisation. Therefore, biomarker responses must be accompanied (or supplemented) by relevant bioindicator endpoints that include community or population-level attributes as a component of ecological risk assessment (Adams 2002).

It is interesting to note that, at this point in time, in the view of some people, "the science of biomonitoring...seems to be coming of age" (Whitfield 2001). Others consider it is still necessary to develop new "cellular and molecular biomarkers as biomonitoring tools", develop "validation and inter-calibration sets of common biomarkers for three different European zones exposed to different pollution impacts" and validate a "methodology for the biomarker use in ecological risk assessment" with the aim of preparing "information and advices to decision-makers and fishery institutions about biological effects of chemical contamination on coastal marine resources". This approach has also been advocated by the NCA (National Coastal Assessment) which uses biological indicators to integrate the various stressors acting on estuarine and coastal environment in the United States (Melzian et al. 2003).

Marine science has become an important pioneer in the development of biomonitoring. The OSPAR convention (Convention for the Protection of the Marine Environment of the North East Atlantic) was a fundamental step, taken in 1992, in which monitoring the effects of certain pollutants on marine organisms by signatory countries became compulsory. The OSPAR JAMP guidelines recommended different types of biological effects monitoring tools for different objectives, i.e. general quality assessment, local impact assessment or contaminantspecific monitoring. As a consequence of the various monitoring techniques, OSPAR classified these techniques into two categories: category I, for which quality assurance procedures are in place, may be used in monitoring and the data are appropriate for conventionwide use; and category II, comprised of techniques for which quality assurance procedures are not yet in place. Although category II techniques may be used for monitoring, caution should be exerted when comparisons are made between data.

As we pointed out in our introduction to the MARS 1 project (Diamant and von Westernhagen 1999), it is important that, in addition to its ability to provide unmistakable results as to the current state of the ecosystem, for a biological effects technique to become widely accepted its application must be as easy and straightforward as possible. These fundamental requirements were the basis on which EU projects such as BEEP (Biological Effects of Environmental Pollution on Marine Coastal Ecosystems), BEQUALM (Biological Effects Quality Assurance in Marine Monitoring) and the Working Group on Biological Effects of Contaminants (WGBEC) were launched. The socio-economic goals of the EU BEEP project, in which 30 partner institutes from 12 countries cooperate, reiterate the necessity for the "development of sensitive cost-effective environmental monitoring systems of biological effects...to provide advice to...politicians and decision-makers about ecological risks of contamination of the marine environment". In agreement with these requirements and those of the third objective of BEQUALM, the MARS project attempted to demonstrate that "biological effects analyses are under statistical control and are of known quality". This 
Table 2 Recommended techniques for biological monitoring programmes at the national or international level (after Anonymous 2002). $I C$ international intercalibration. $B$ BEQUALM; $Q$ QUASIMEME; $O$ other. Source: Anonymous (2002)

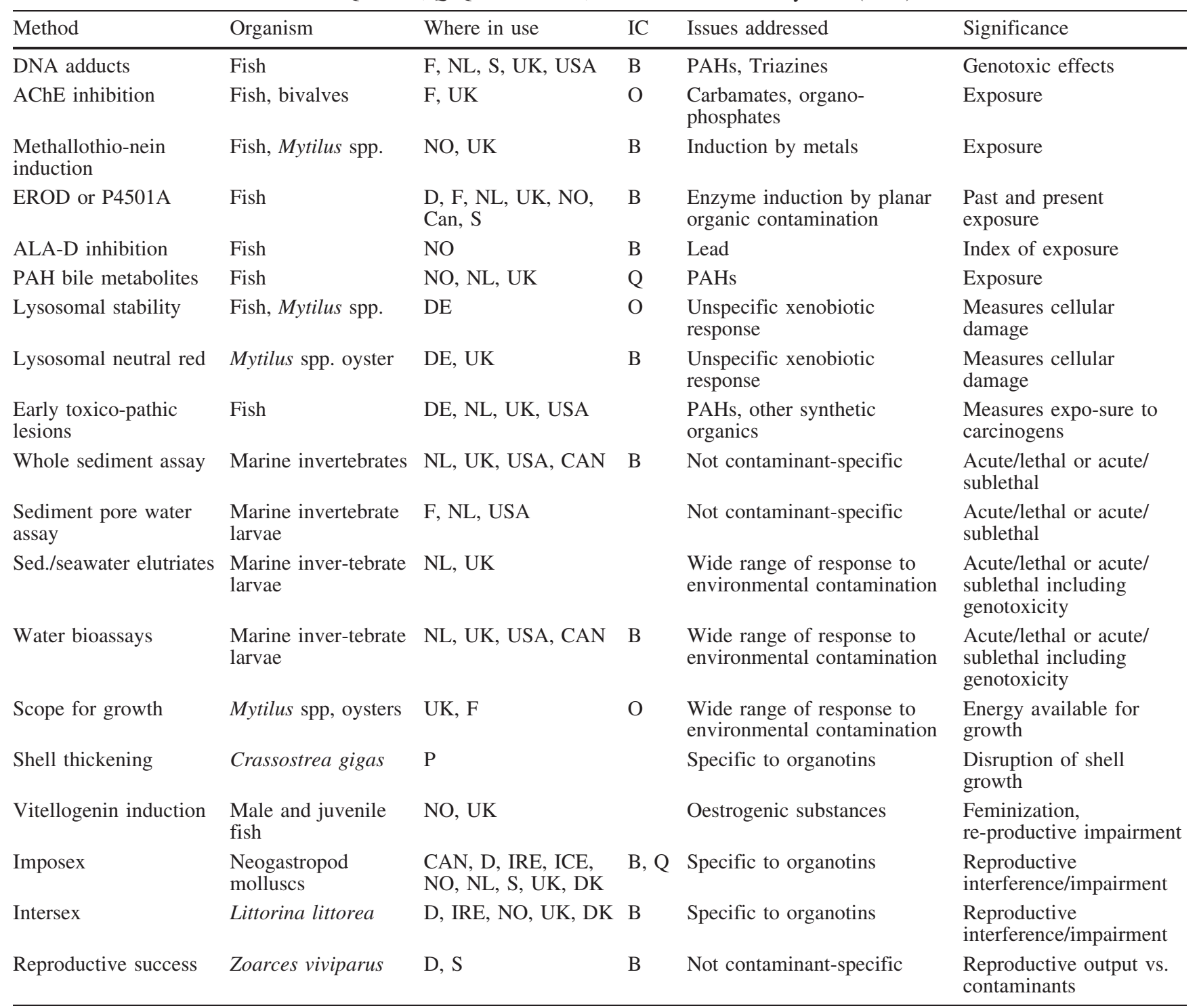

prerequisite for standardisation and wide acceptance of biological effects monitoring methods is essential in order to "get the foot in" the regulators" door. When OSPARrecommended guidelines were first implemented, it became clear that lack of standardisation of methodologies used for measuring levels of heavy metals, chemicals, radio nuclides, crude oil and other pollutants was the major weakness. Comparison of measurements made by different laboratories turned out to be extremely difficult, if not impossible. One of the major concerns in MARS was precisely this difficulty. This problem was compounded by the fact that participating teams set out to choose and select target species to act as indicator organisms, but at the same time set out to develop new biomarkers and indices. Thus, the objective was to focus on a diverse group of organisms living in (as much as possible) the same habitat on which several new ap- proaches, and well-established and proven techniques, would be tested. The Mars 1 project also addressed the previously mentioned issue of combining chemical background data with early-warning biomarkers for ecosystem stress detection. In 1995, when MARS 1 was initiated, its objectives were the development of new, if possible not region-specific, techniques, while in 1998, when the second phase (MARS 2) was begun, the objectives were to prove the validity of the chosen techniques-including the choice of species.

MARS was designed to combine a variety of biomarkers and bioindicators (sensu Adams 2002) to evaluate both organism stress effects and higher level responses for anthropogenically generated impacts on the marine ecosystem. In addition, the efficacy and value of selected techniques over a large geographical range, for the sake of inter-comparison, was attempted. A general map of the 
Fig. 1 Sampling areas in different geographical locations of the North Sea, Mediterranean Sea and Red Sea. Approximate areas are marked with circles (source: Diamant and von Westernhagen 1999)
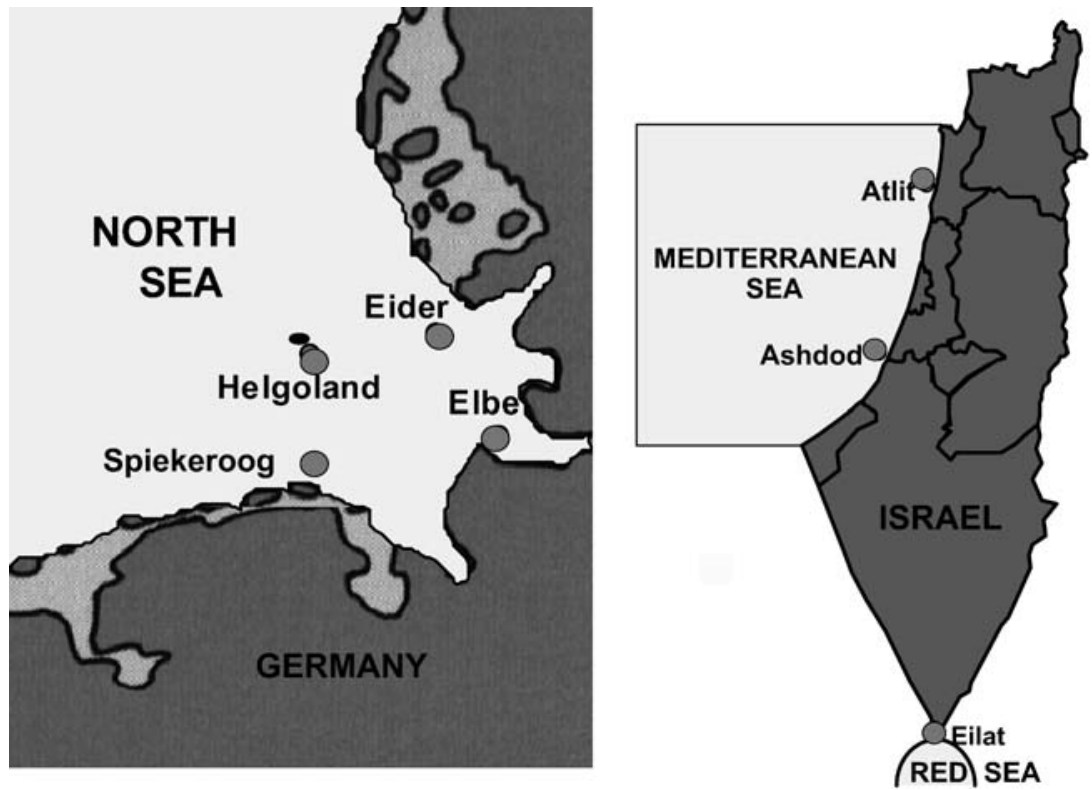

Table 3 Parameters considered in the MARS project

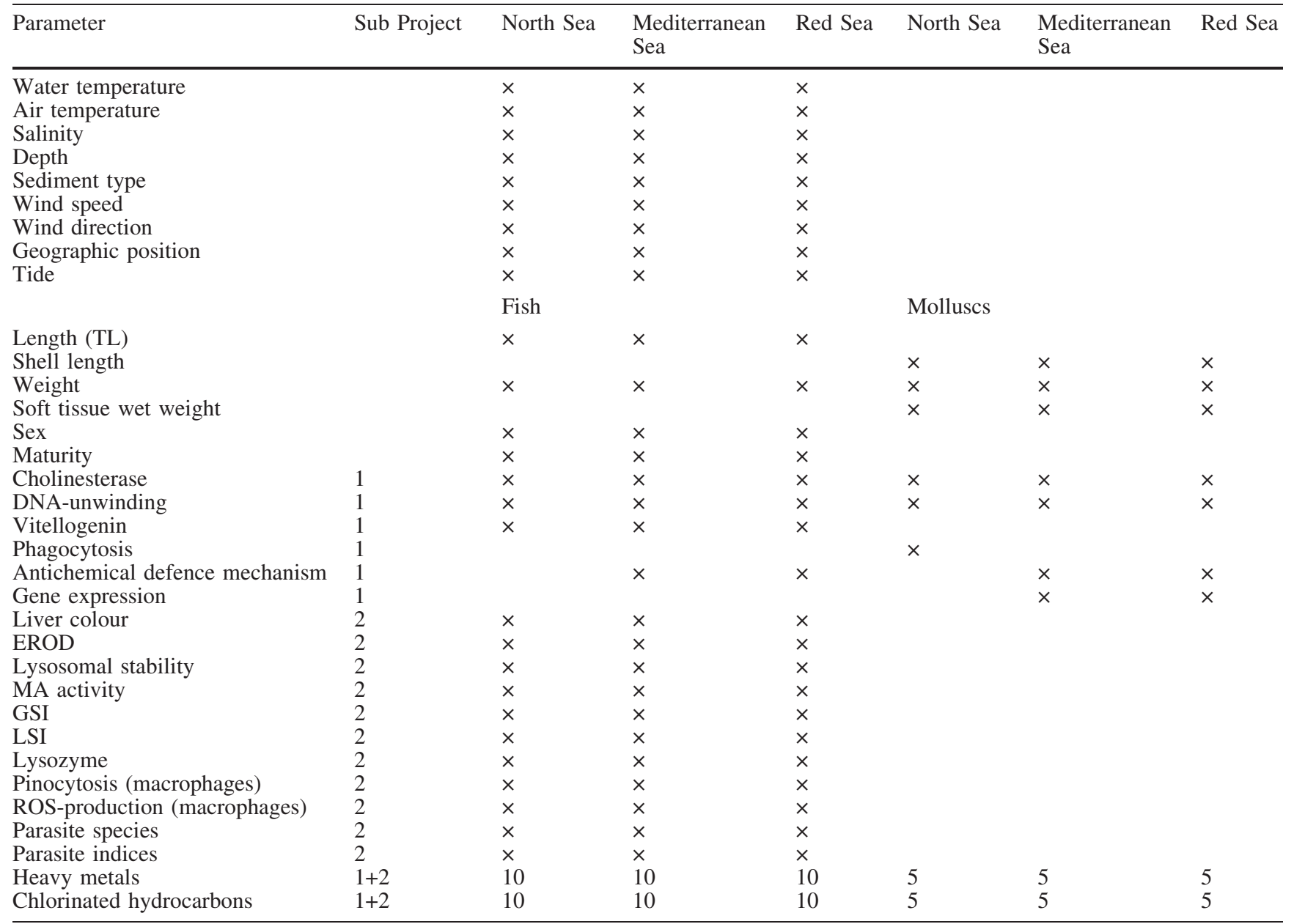


sampling areas is given in Fig. 1. Due to obvious practical considerations, the German groups focused mainly on the North Sea while Israeli groups focused on the Mediterranean and Red Seas; however, joint field sampling, shared processing and common analyses were carried out on a regular basis. Sampling strategies, sample size and parameters in the MARS project were coordinated between the sub-projects with the help of the statistical group (MARS 2 Statistics) linked with the project. The measured parameters are shown in Table 3. The sampling strategy adopted was a result of the two sub-projects' internal discussion during the MARS 1 "kick-off workshop" in Jerusalem, Israel on 27-31 January 1995. The plan was intended to include as many parameters as reasonably possible in the overall integrated statistical and ecological evaluation of the entire database. For particular parameters such as species and sites, no defined common statistical grounds were available, thus triggering the need to reduce the number of parameters in the overall evaluation process. In such instances, separate regional evaluations (i.e. North Sea, Mediterranean Sea and Red Sea) were carried out.

\section{Sampling strategy}

As a general rule, 20 fish specimens per station per sampling campaign were analysed/investigated. Molluscs were processed in pools of five individuals per sample. Five pools per station per sampling campaign were examined.

\section{Residue analysis}

Chemical analyses were conducted for standard chlorinated hydrocarbons and heavy metals in ten fish samples and five mollusc pools per station per campaign. In addition, one sediment sample per year was analysed at each location.

\section{The North Sea}

Sampling was carried out in April and September at the Elbe River, Norderpiep (fish only), Spiekeroog, Weser River (fish only), Inneneider, Tiefe Rinne (fish only) and Helgoland Düne (bivalves only).

The target species were: fish-flounder Platichthys flexus; and mollusc_-mussel Mytilus edulis

\section{The Mediterranean Sea}

Sampling was carried out in March and October at Haifa Bay and Maagan Michael

The target species were: fish-grey mullet Liza ramanda, L. aurata; and molluscs-Donax trunculus, Patella caerulea and Brachidontes pharaonis.

\section{The Red Sea}

Sampling was carried out in March and October at North Beach, mariculture cage farms, and the IUI/MBL/UW Observatory (Coral reef)

The target species were: fish-rabbitfish Siganus rivulatus; and molluscs-Pteria aegyptia and Cellana rota.

\section{MARS 1995-2001: biomonitoring in three marine regions}

The MARS project took place during the turn of the $2 \mathrm{nd}$ millennium, an era that is likely to become an environmental turning point in the history of the Earth's oceans. The current over-harvesting of natural populations, razing of coastal ecosystems, destruction of coral reefs, pollution of estuaries and relentless movement of species between geographical regions are examples of rapidly altering marine environments. Some eye-opening statistics listed at the 2002 meeting of the American Association for the Advancement of Science are worth repeating here: over the past half century, one third of the world's forests and one fifth of its topsoil have been lost, and agricultural expanses are being doused with toxic pesticides at an annual rate of 3 million metric tons. A good deal of this eventually reaches the ocean, but how much is largely unknown. Man has altered the composition of the atmosphere to the extent that stratospheric ozone levels are close to depletion, and global warming has been associated with mass mortality of coral reefs; and two thirds of the world's fisheries have now reached a stage of being harvested beyond sustainability (Raven 2002). Thus, from a global perspective, we are no more optimistic regarding the marine environment than we were at the MARS kick-off meeting in 1995.

The work was carried out in three different seas representing distinct climates.

\section{The North Sea}

Since the last Quality Status Report (QSR) of the North Sea was issued in 1993, the number of people living in the countries around it has increased by $10 \%$. Consequently, changes in the quality and quantity of human impact have occurred. Yet the North Sea ecosystem "continues to suffer from a number of old problems, sometimes showing some signs of amelioration, but also new problems have arisen. Effects of hazardous substances, eutrophication and direct as well as indirect impacts of fisheries comprise the most important issues" (North Sea Task Force 1993). In many ways, however, there has been an improvement in the environmental status since the 1993 QSR, such as a reduction in the inputs of cadmium, mercury and lead and a generally decreasing level of PAHs and some organochlorines measured in organisms. 
The input of oil in discharges has likewise been considerably reduced.

With respect to nutrients, there has been an overall reduction in the input of phosphorus in the order of 50\% as well as a $30 \%$ decrease of the direct inputs of nitrogen. Other contributions to the reduction of human pressure since 1993 are the cessation of the dumping of sewage sludge and other industrial wastes, as well as a cutback in the use of a number of chemicals in mariculture.

With respect to other human pressures, however, no general improvement is visible. A number of areas still suffer from eutrophication, and concentrations of the antifouling agent TBT still exceed safe levels in marinas. Inputs of contaminants in the open sea are mainly from the offshore oil and gas industry, for an increasing part through the discharge of produced water, oil, PAHs, phenol compounds (possible endocrine disruptors) and chemicals used in the production process. Some persistent contaminants still reach high levels in the sea at places where they are concentrated, such as sedimentation areas (in particular the Skagerrak and Norwegian Trench).

Fishing still exerts a major impact on the North Sea ecosystem through the removal of target species, discarding of non-target species and the physical disturbance of the sea bed. Many fish stocks are being fished above safe biological limits, and by 2002 the cod stock of the North Sea had practically collapsed.

In general, human pressures are greatest and impacts are most visible in the coastal zones and in estuaries situated in highly industrialized areas such as the Seine, Western Scheldt, Rhine/Meuse mouth, Ems, Weser, Elbe, Forth, Humber and Thames. At some Norwegian fjords which are relatively sensitive to human pressures due to limited water exchange, and at some locations along the Scottish coast, mariculture can be a significant source of contamination, including the introduction of diseases and non-indigenous species. Many coastal habitats in the southern part of the North Sea, such as intertidal areas, wetlands and salt marshes, have vanished due to draining, erosion or the construction of coastal defence structures. These zones, in particular sandy coasts, have also been severely disturbed due to recreational activity.

\section{The Mediterranean Sea}

Public awareness of environmental issues regarding the Israeli marine coastline is on the rise. This vigilance, coupled with the establishment of a government system responsible for the implementation of environmental policies, has helped limit and control pollution levels in both the Mediterranean and Red Seas in the last 20 years. Nevertheless, there is a decline in the environmental health of both Mediterranean and Red Sea shorelines of Israel. The drop in biodiversity on these coasts has been unequivocally attributed to anthropogenic impact (Fishelson 1995, 2000).

The Mediterranean Sea is considered one of the world's most environmentally impacted seas. The annual input of contaminants from ships, urban centres, industrial parks and agricultural runoff is immense. Nearly half of the coastal urban centres still lack sewage treatment facilities. An estimated half a million tonnes of raw sewage, pesticides and fertilizers, 60,000 tonnes of detergents, 12,000 tonnes of oil, $>200$ tonnes of chromium and $>100$ tonnes of mercury are dumped into it annually. Although it comprises only $3 \%$ of the global ocean surface, the Mediterranean sustains some $30 \%$ of the world volume of shipping activity, and ballast waters add thousands of exotic marine organisms every year. It is estimated that $80-100$ years are required for one full change of water through the Gibraltar straits and thus, at the current input rate, pollutants are accumulating faster than they are removed.

Pollution hot spots in the eastern basin include eastern Greece, Egypt and Israel. In addition to the human activity along the shores, the creation of the Suez Canal waterway in 1869 and Aswan Dam construction in the 1960s have had their own great impact. The Suez passage has brought about an influx of Indo-pacific species into the Mediterranean, enriching the so-called "species impoverished" eastern basin with 'Lessepsian' migrant species. In a recent survey, this process, viewed by some as detrimental and others as beneficial (Galil 2000; Fishelson et al. 2002), was estimated to have contributed over 1,000 (of 12,000 species) of selected taxonomic phyla to the Mediterranean, mostly of Eritrean origin (Golani et al. 2002). Another event was the construction of the Aswan High Dam in Egypt on the upper Nile, which has since prevented the seasonal river flood waters reaching the Mediterranean. The diminishing coastal nutrient levels and Nile Delta phytoplankton blooms caused a collapse of the southern Levant sardine Sardinella aurita fishery that depended on it.

Israel's $190 \mathrm{~km}$ coastline is over-fished, with such species as hake, red mullet, sole, tuna and grouper subjected to overexploitation for many years.

As a signatory of international marine pollution prevention treaties, Israel benefits from legislation and implementation of environmental laws. There is a striving for increased water recycling in industry and reduction of effluent outflow from land sources. With the establishment of the National Sewage Project, state-of-the-art water treatment technology and control systems have been introduced. However, failures still occur. For example, in spring 2003 a breakdown of the Dan (Tel Aviv) sewage system resulted in a prolonged, massive dumping of raw sewage into the adjoining sea. The resulting contamination of the Tel Aviv coastline was severe, and local marine fishery came to a virtual standstill since consumers were concerned that fish sold on the market may have originated from the polluted areas. As a result, fish consumption, including from aquaculture and freshwater sources, dropped sharply for many weeks.

Overall, levels of pollution along the Israeli Mediterranean coastline are regarded by some to be no higher at present than the acceptable international criteria for 
marine environmental quality. However, serious focal hot-spots remain, the most serious probably being the Kishon harbour estuary of Haifa Bay. This site was among the sampling stations of several of the MARS subprojects. The high levels of pollutants in this river have recently been claimed as the major cause for elevated incidence of malignancies amongst Israeli Navy divers who train in its waters and fishermen who use the Kishon as their home port.

\section{The Red Sea}

Tropical coral reefs thrive in clear oligotrophic waters (Rinkevich and Loya 1984). The Gulf of Eilat is famous worldwide for its crystal clear water and spectacular coral reefs that have been considered to support the highest coral diversity recorded anywhere (Fishelson 1971). This region experienced an enhanced economical development in wake of the Israeli-Arab peace process at the end of the 20th century (IUI 1994, 1995, 1996). The reefs have been degrading rapidly as urbanization and development altered and progressively destroyed coastal habitats. In Jordan, local disturbance of coral reefs has led to a $50 \%$ decline in overall fish abundance, especially invertebrate feeders and piscivores. At the same time, the abundance of herbivores, detritivores and planktivores was seen to increase (Khalaf and Kochzius 2002). The decline of the reefs is attributed by some researchers to the persistent influx of nutrients from urban sewage and mariculture activity, claiming that oligotrophic conditions necessary for the thriving of coral have changed, increasing turbidity and boosting phytoplankton biomass near the northern coastline (Lazar et al. in IUI 2001; Cariou and Erez in IUI 2001). A model depicting the seasonal vertical mixing of the water column as a factor in generation of macro-algal blooms and resulting coral reef degradation has been proposed (Erez et al. in IUI 2001). There is also evidence for deterioration of sea grass beds and appearance of introduced exotic fish species. Observations and field data collected over the years indicate an increase in breakage of reef-building coral branches, decline in coral species diversity and recruitment rates and overall number of live coral colonies in Eilat's nature reserve (Zakai and Chadwick-Furman 2002). There is an increased incidence of diseased coral (Sussman et al. 2003) and fish, shown to be linked with anthropogenic activity (Diamant et al. 2000; Diamant 2001; Colorni et al. 2002).

At the same time, other studies present contradictory results. A recently completed long-term study of the ichthyofauna of Eilat's sandy north shore suggests that no significant changes have occurred in the fish communities between 1984 and 2001 (Golani and Lerner in IUI 2001), while rapid growth of hermatypic corals on mariculture cages at farm sites has been reported by others (S. Shafir and B. Rinkevich, unpublished data).

The dispute regarding Eilat's cage farms coincided with a widening trend in criticism of salmon and shrimp mariculture in various parts of the world. In a recent review paper, Naylor et al. (2000) detailed the environmental impacts attributed to marine aquaculture, including discharge of nutrients and toxic chemicals, transfer of diseases and parasites to wild stocks, introduction of exotic species and genetically modified strains into the environment, modification of food webs and loss of habitat and niche space. In the course of MARS 2, in view of the public controversy on the environmental effects of Eilat's mariculture cage farms, an International Expert Team (IET) was appointed by the Israeli government to independently evaluate the available scientific evidence and recommend steps to ameliorate the gulf ecological situation. The IET pointed at three major sources of pollution in the northern Gulf of Eilat: mariculture cage farms, harbour phosphate terminals and urban sewage effluents (Atkinson et al. 2001). Additional factors, of lower significance, were groundwater inputs, siltation, marina activities, oil, tourism, sports diving activity and port ballast water. Also, increased water temperature due to global causes was identified as a possible contributing factor. The IET found no unequivocal link between mariculture cage farm activities and declining coral reefs located $8 \mathrm{~km}$ away and advocated a regional 'environmental carrying capacity' of a sustainable cage mariculture encompassing fish production of approximately 2,500 tons/yr, pending specific management steps (Atkinson et al. 2001).

\section{MARS: assessment of the outcome}

In MARS, the work carried out in these three seas attempted to develop a suite of general community-level indicators of stress for marine ecosystems. More specifically, the scientific output expected from the work was "the development of a reliable and reproducible set of biological tests for environmental risk assessment". As stated in the initial phase, the "tests should include as many different levels of biological organizations in one single individual as possible to obtain information on how far the disturbance of the system due to the influence of environmental toxicants has advanced".

The community is viewed as not only an integrative multi-species indicator of stressors acting at a range of lower levels of organization but also the most ecologically relevant indicator, because effects can be directly extrapolated to the ecosystem (Attrill and Depledge 1997; Attrill 2002). In this context, the community is defined after Mills (1969) as “.... group of organisms occurring in a particular environment, presumably interacting with each other and with the environment, and separable by means of ecological survey from other groups". Although biological systems are known to be hierarchical in nature (Rosen 1969), simplified diagrams linking the levels of biological organization may suggest a linear model reaction that ignores the emergent properties of these systems. These emergent properties are often the cause of unpredictable variability (Drake 1991), and have important consequences for bioindicator studies, as many 
MARS 2 Bioindicator levels

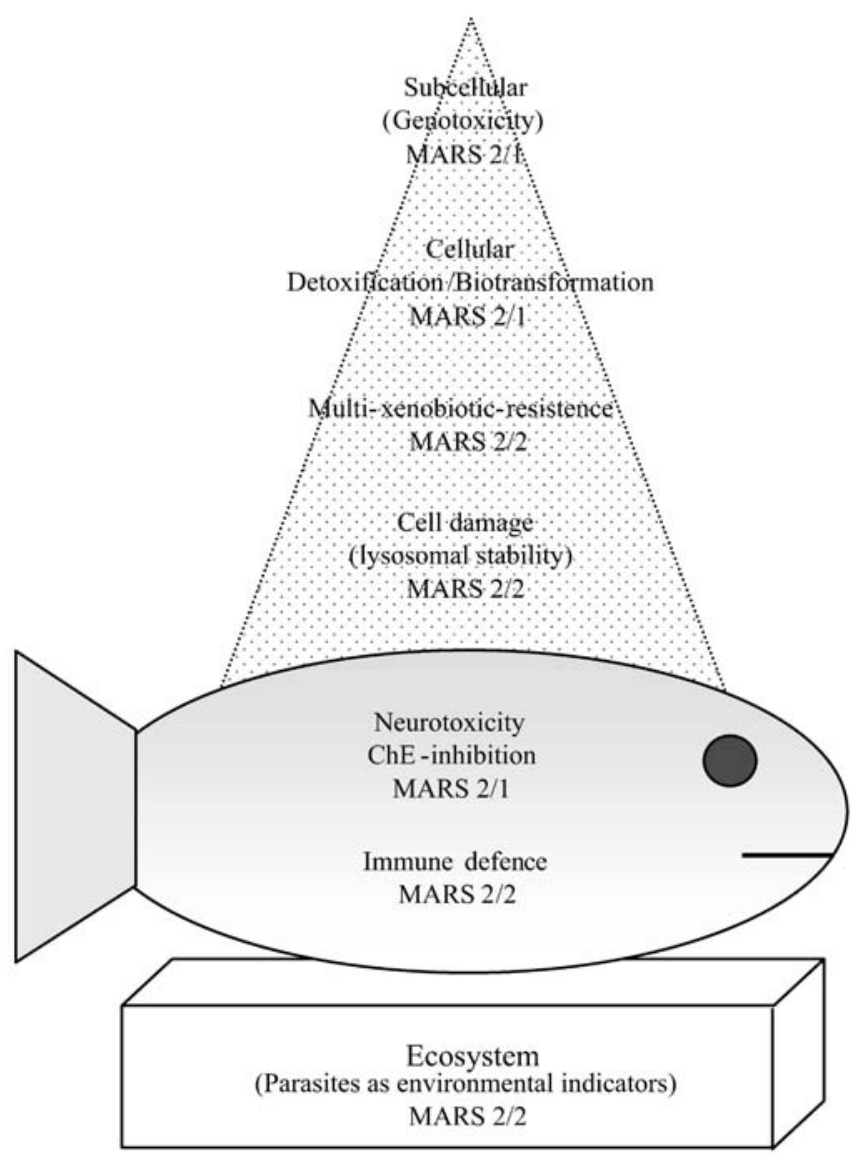

Fig. 2 A schematic representation of the different levels of biological organisation in an individual (fish) as addressed by the different MARS working groups

studies aim at providing a method targeted at lower levels of biological organization that will predict response at higher levels, for instance communities. Thus, biomarkers at lower levels of biological organization are potentially useful for assessing stress effects, but they must be correlated and calibrated using accompanying investigations at an ecologically relevant level (McCarty and Munkittrick 1996), such as the community. Only when the emergent properties of a system are fully described can selection of variables and analysis at lower levels be undertaken (Kerr 1976). Only a carefully calibrated biomarker that correlates with community response may then be called a "valid biomarker". Studies solely employing low level biomarkers that correlate with contamination cannot be used to predict higher level response. It is for this reason that the MARS approach tried to incorporate diverse levels of response-and we should at this stage take a closer look at what resulted from this approach and whether the initial goal was achieved, keeping in mind the ultimate applicability of our findings. For this purpose, a brief presentation of the nature of the MARS projects is helpful for visualising the different levels of biological organisation investigated (Fig. 2). Fig. 2 indeed demonstrates how a variety of organizational levels in an individual (fish) were addressed by the different MARS working groups.

\section{Potential application of methods evaluated in MARS}

The methodology presented by Bresler et al. in which fresh animal tissue is analysed by specialised fluorescent probes and contact microscopy yielded excellent results. The research clearly showed differences between polluted and reference sites in exclusion of hazardous agents by biological membranes and deployment of anti-xenobiotic export pumps), in function of intracellular defence mechanisms (e.g. metallothionein) that act to minimise potential damages of agents that do get into the cell, and in appearance of DNA breaks, DNA unwinding and other pathological alterations when xenobiotics gained entrance at high concentration. Bresler et al. showed that an early warning against environmental pollution can be based on this combination of defence mechanism activity and damage assessment. In the words of Bresler et al. "the various parameters studied unravel complex biological responses to environmental pollution, at the cellular and molecular levels. The types and levels of responses studied here may be viewed as the raw material for future, refined studies, by which specific diagnostic kits may be 'tailored' to meet the needs of specific coastlines".

The use of the activity of acid phosphatase in liver macrophage aggregates (MA-AP) of different fish species as a marker for the pollution induced modulation of the digestive capacity of phagocytes was evaluated by Broeg. Based upon the investigation of more than 900 individual flounders (Platichthys flesus) and mullets (Liza aurata), natural variations, gender-specific differences and pollution-induced alterations in AP activity were demonstrated. Nevertheless, distinctions between differently polluted areas were visible in all sampling campaigns, with the lowest MA-AP activity in fish sampled at the polluted areas of the German Bight and the Israeli Mediterranean. For organochlorine contaminants, as well as for mercury and copper, a significant suppression of MA-AP activity was observed, leading to the conclusion that MA-AP activity in fish could be a reliable biomarker for the application in environmental health assessment exercises.

Schmidt et al. and Dzikowski et al. analyzed the constraints of employing parasite community indices in pollution monitoring. One basic shortcoming in all areas was that although many of the fish parasite species were relatively well studied, the effects pollutants have on them are still largely unknown. One of the greatest problems encountered by Schmidt et al. in the North Sea fish was that the monitored parasite species had a patchy distribution and could not be found at all investigated locations. Also, their considerable sensitivity to salinity complicated the interpretation of the results. Schmidt et al. concluded that a better understanding of the biology of flounder 
parasites was needed before they could be used as reliable pollution bioindicators. In the studies of fish parasites in the Mediterranean and Red Sea, Dzikowski et al. assessed the validity of implementing the cumulative species curve model that extrapolates "true" species richness of a given habitat as a function of increasing sample size. The analyses considered heteroxenous and monoxenous parasite species separately for each site and the generated curves yielded clearly significant results in both seas. These results provided the sought after differential characterisation of parasite communities in differentially impacted sites. Based on these results, as well as those of MARS 1/2 (see Diamant et al. 1999), the authors considered that the tested methodology can be implemented in integrated environmental monitoring programs. Consequently, the upcoming Israeli National Monitoring Plan of the Red Sea will routinely include use of this bioindicator.

Considering physiological parameters of fish as biomarkers, Skouras and Steinhagen showed that leucocyte cell suspensions derived from flounder head kidney may be directly used, without enrichment protocols, in respiratory burst assays. Lysozyme activity can be recorded from flounder plasma in a simple turbidometric assay, evaluated by means of a microtitre plate reader. These authors conclude that both assays may be implemented in field studies and are ready for use in integrated programs of environmental monitoring. The work of this group also suggests that biological effects of environmental contaminants can be monitored in the "field" by means of immunological assays. By observing innate immune parameters in conjunction with other physiological data from the same fish individuals, it was possible to examine the effects of pollution. Cellular function, such as uptake of neutral red, was impaired in individuals with increased proportions of DNA adducts or decreased lysosome stability. The activity of plasma lysozyme decreased in individuals with impaired lysosome stability, and showed some correlation to cytochrome P450 1A induction. Thus, Skouras et al. suggest that these innate immune parameters may be incorporated into a battery of parameters in future integrated monitoring programs.

Gefen et al. attempted to present an integrated and coherent view of how the developed methods hang together. They analysed all results in a comparative study, and demonstrated that the MARS bioindicators were to a large degree successful. Almost all were sensitive enough to separate the cleaner reference sites of a region from other surrounding polluted sites, with statistical significance. A theoretical model of hostparasite population dynamics that makes the presence of ecological thresholds transparent is offered to help explain abrupt transitions prominent in parasite distribution at different sites. Heavy metal and chlorinated hydrocarbon data collected in fish and mollusc tissue have been assessed as bioindicators but appear to be less sensitive than changing parasite community structure. In contrast, levels of tissue damage and active transport system activity levels in molluscs are found to have great potential as bioindicators.

Based on the results of MARS, it is possible to select markers for routine biomonitoring of the marine environments studied. However, in order to serve not only for monitoring, but also for warning, the selected markers must be able to expose biological responses as early as possible. Preferably, the 'signal' produced by the markers should enable the grading of environmental problems on a locally relevant scale. That is, sites polluted to a different degree should manifest quantitatively different responses. Although simplistic and possibly even crude, some of the standard ecological indices proved very effective in testing hypotheses regarding changes in community structure. Their effectiveness was especially enhanced through the use of powerful multivariate statistical tools such as principal component analysis. More delicate bioindicators, such as those based on biochemical tests designed to assess an organism's defence mechanisms and measure damage to the organism's pathology, have the potential to be exceptionally sensitive indicators of pollution.

The analysis of the MARS 2 bioindicators reconfirmed the initial environmental gradients obtained from the earlier MARS 1 analyses, giving further support to the hypothesis that the reference sites chosen were all indeed the cleaner of the regional sites. Assignment of reference sites was a controversial issue that was queried many times throughout the MARS project. The MARS 2 results do not contradict the initial assignment, although in the North Sea, for example, it was difficult to discriminate an environmental gradient where pollution levels were in any case minimal.

\section{Concluding remarks}

The development of a new biomonitoring method is a very important step. However, as anyone involved with environmental assessment work is well aware, its adoption by decision-makers and implementation by regulating agencies is quite a different matter. This requires a multitude of additional scientific and administrative efforts. Accordingly, the techniques proposed as valuable methods for biological effects monitoring within the MARS framework will have to pass the standard procedural hurdles including calibration, rigorous interpretation and verification of results. Then, the methods will be discussed by the responsible regional scientific bodies, such as the Working Group on Biological Effects of Contaminants (WGBEC) of the ICES (in the case of North Sea affairs on an international level). There, in the WGBEC, the proposed methods will be further scrutinised in detail (and at length) and either added to the inventory already on the long list of 'Recommended techniques for biological monitoring programmes at the national or international level' or, which is more likely at the level that the methods are at present, on the list of 'Promising biological effects monitoring methods which 
require further research before they can be recommended for monitoring' (Anonymous 2002, Tables 8.1 and 8.2).

Another way to make immediate use of a newly developed monitoring method is the employment of this method on a regional scale as an addition to currently accepted programmes. This approach may be described as an "adaptive management" process, in which new monitoring results are used to guide management decisions and to refine the monitoring programme (Healey and Hennessey 1994). Such a concept is being used by the National Research Council (NRC 1993) and has been effective in promoting continuous feedback loops between management decisions and monitoring and research.

Coastal marine ecosystems are governed by a vast array of natural processes, including a growing list of anthropogenic stressors. The planet Earth is now completely at the mercy of a single species, Homo sapiens, and our actions will largely determine the future of the planet, including the oceans that cover over $60 \%$ of its surface. Time will tell whether we succeed in stopping the spiralling surge of global warming, droughts, floods, famines and declining biodiversity and put Earth back on the right path of a vital planet with a healthy environment. Indeed, obtaining this common goal, the fostering of the marine environment, will have to rely on active international cooperation. The participants of MARS, perhaps in an infinitesimal way, have shown that excellent scientific results can be obtained when resources, effective teamwork and collaborative efforts are combined. We hope the outcome of MARS will not only expand our understanding of basic biological processes but that the newly developed bioindicators will quickly find their way into national and international integrated monitoring programmes.

Acknowledgements Special thanks are due to Helmut Bianchi (GKSS, Germany) and Nurit Topaz (MOS, Israel) whose constant efforts to keep the MARS project on the right track despite difficulties that sometimes seemed positively insurmountable enabled the completion of the work and publication of this issue.

\section{References}

Adams SM (2002) Biological indicators of aquatic ecosystem stress: introduction and overview. In: Adams SM (ed) Biological indicators of aquatic ecosystem stress. American Fisheries Society, Bethesda, Md., pp1-11

Anonymous (2002) Report of the Working Group on Biological Effects of Contaminants. ICES CM 2002/E:02. Ref. ACME

Atkinson MJ, Birk Y, Rosenthal H (2001) Evaluation of pollution in the Gulf of Eilat. Report for the Ministries of Infrastructure, Environment and Agriculture

Attrill MJ (2002) Community-level indicators of stress in aquatic ecosystems. In: Adams SM (ed) Biological indicators of aquatic ecosystem stress. American Fisheries Society, Bethesda, Md., pp473-508

Attrill MJ, Depledge MH (1997) Community and population indicators of ecosystem health: targeting links between levels of biological organisation. Aquat Toxicol 38:183-197
Colorni A, Diamant A, Eldar A, Kvitt H and Zlotkin A (2002) Streptococcus iniae infections in Red Sea cage-cultured and wild fish. Dis Aquat Org 43:165-170

Diamant A (2001) Cross infections between marine cage-cultured stocks and wild fish in the northern Red Sea: is the environment at risk? Proceedings of the 1st OIE International Conference on Risk Analysis in Aquatic Animal Health. Office International Epizooties, Paris, 8-10 February

Diamant A, von Westernhagen H (1999) Biological indicators for the detection of natural and man-made changes in coastal waters - an introduction to the MARS project. Helgol Mar Res 53:148-153

Diamant A, Banet A, Paperna I, von Westernhagen H , Broeg K, Krüner G, Koerting W, Zander S (1999) The use of fish metabolic, pathological and parasitological indices in pollution monitoring. II. The Red Sea and Mediterranean. Helgol Mar Res 53:195-208

Diamant A, Banet A, Ucko M, Colorni A, Knibb W, Kvitt H (2000) Mycobacteriosis in wild rabbitfish Siganus rivulatus associated with cage farming in the Gulf of Eilat, Red Sea. Dis Aquat Org 39:211-219

Drake JA (1991) Community-assembly mechanics and the structure of an experimental species ensemble. Am Nat 137:1-26

Fishelson L (1971) Ecology and distribution of the benthic fauna in shallow waters of the Red Sea. Mar Biol 10:113-133

Fishelson L (1995) Elat (Gulf of Aqaba) littoral: life on the red line of biodegradation. Isr J Zool 41:43-55

Fishelson L (2000) Marine animal assemblages along the littoral of the Israeli Mediterranean seashore: the Red-Mediterranean seas communities of species. Ital J Zool 67:393-415

Fishelson L, Bresler V, Abelson A, Stone L, Gefen E, Rosenfeld M, Mokady O (2002) The two sides of man-induced changes in littoral marine communities: eastern Mediterranean and the Red Sea as an example. Sci Total Environ 296:139-151

Galil BS (2000) A sea under siege: alien species in the Mediterranean. Biol Invasions 2:177-186

Golani D, Orsi-Relini L, Massuti E, Quignard JP (2002) CIESM atlas of exotic species in the Mediterranean. CIESM Publ., Monaco

Healey MC, Hennessey TM (1994) The utilization of scientific information in the management of estuarine ecosystems. Ocean Coast Manage 23:167-191

IUI (1994) The ecosystem of the Gulf of Aqaba in relation to the enhanced economical development and peace process-I. The Interuniversity Institute for Marine Sciences in Eilat, 18-20 January 1994

IUI (1995) The ecosystem of the Gulf of Aqaba in relation to the enhanced economical development and peace process-II. The Interuniversity Institute for Marine Sciences in Eilat, 30 January-2 February 1995

IUI (1996) The ecosystem of the Gulf of Aqaba in relation to the enhanced economical development and peace process-III. The Interuniversity Institute for Marine Sciences in Eilat, 22-25 January 1996

IUI (2001) Abstracts of the 33rd anniversary conference of the Interuniversity Institute of Marine Sciences, Eilat, 21-25 October 2001

Kerr SR (1976) Ecological analysis and the Fry paradigm. J Fish Res Bd Can 33:329-335

Khalaf MA, Kochzius M (2002) Changes in trophic community structure of shore fishes at an industrial site in the Gulf of Aqaba, Red Sea. Mar Ecol Prog Ser 239:287-299

McCarty LS, Munkittrik KR (1996) Environmental biomarkers in aquatic toxicology: fiction, fantasy or function? Hum Ecol Risk Assess 2:268-274

Melzian BD, Engle V, McAlister M, Sandhu S, Eads LK (eds) (2003) Coastal monitoring through partnership. Special Issue. Environ Monit Assess 81:1-408

Mills EL (1969) The community concept in marine zoology, with comments on continua and instability in some marine communities. J Fish Res Bd Can 26:1415-1428 
Naylor RL, Goldburg RJ, Primavera JH, Kautsky N, Beveridge MC, Clay J, Folke C, Lubchenco J, Mooney H, Troell M (2000) Effect of aquaculture on world fish supplies. Nature 405:10171024

North Sea Task Force (1993) North Sea Quality status report 1993. Oslo and Paris Commission, London: Olsen and Olsen, Fredensborg, Denmark

NRC (1993) Research to protect, restore, and manage the environment. National Research Council, Committee on Environmental Research, Tel Aviv

Raven PH (2002) Presidential address. Science, sustainability, and the human prospect. Science 297:1477

Rinkevich B, Loya Y (1984) Does light enhance calcification in hermatypic corals? Mar Biol 80:1-6
Rosen R (1969) Hierarchical organization in automata theoretic models of biological systems. In: White LL, Wilson AG, Wilson D (eds) Hierarchical structures. Elsevier, New York, pp.179-199

Sussman M, Loya Y, Fine M, Rosenberg E (2003) The marine fireworm Hermodice carunculata is a winter reservoir and spring-summer vector for the coral-bleaching pathogen Vibrio shiloi. Environ Microbiol 5:250-255

Whitfield J (2001) Vital signs. Nature 411:989-990

Zakai D, Chadwick-Furman NE (2002) Impacts of intensive recreational diving on reef corals at Eilat, northern Red Sea. Biol Conserv 105:179-187 